\title{
Seroprevalence of tetanus antibodies among pregnant women in Duhok Governorate, Iraq
}

\author{
L. Hurmez, ${ }^{1}$ Q.S. Habeeb ${ }^{2}$ and N.A. Al-Derzi ${ }^{3}$
}

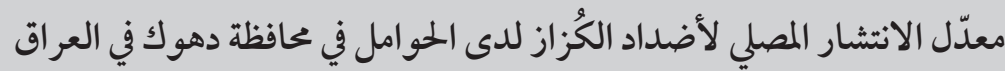

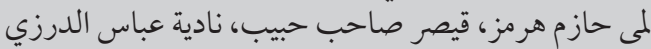

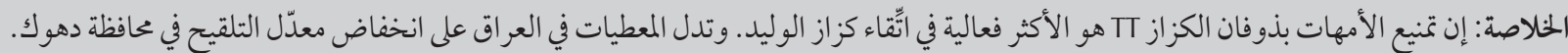

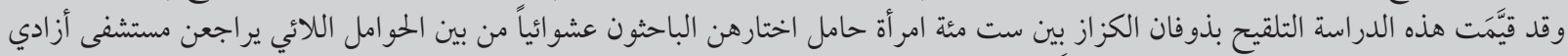

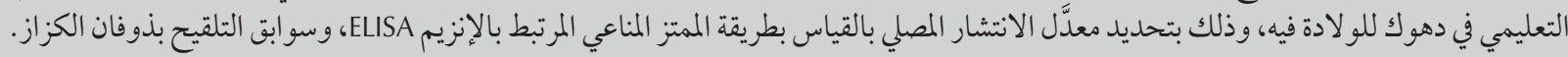

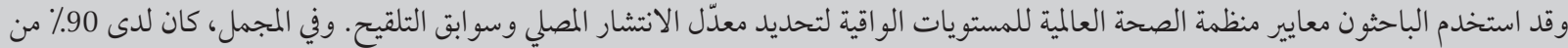

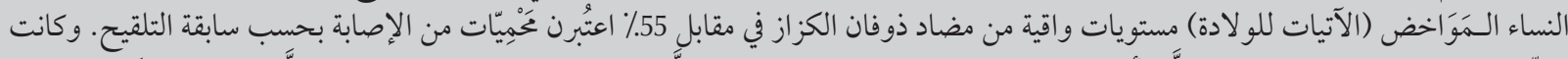

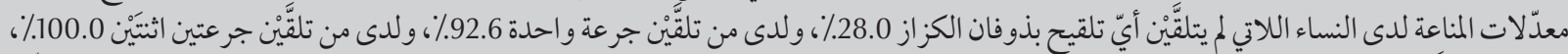

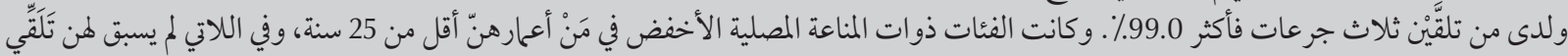

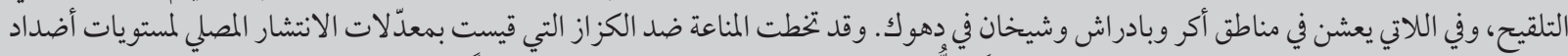

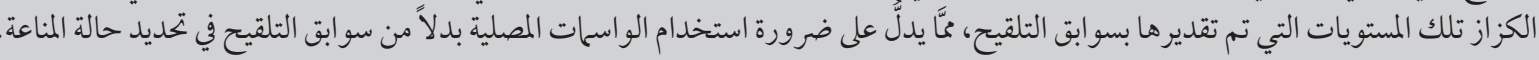

ABSTRACT Maternal immunization with tetanus toxoid (TT) is the most effective was to prevent neonatal tetanus. In Duhok, Iraq data indicate low vaccination coverage. This study assessed TT immunization status among 600 randomly selected pregnant women attending Azadi teaching hospital, Duhok for delivery, by both tetanus antibody seroprevalence and TT history. WHO criteria for protective levels were used for seroprevalence and vaccination history. Overall, $90 \%$ of the women at delivery had protective tetanus antitoxin titres compared to only $55 \%$ considered protected according to their vaccination history. Immunity rates for women who had received no $T$ T vaccination, 1 dose, 2 doses and $\geq 3$ doses were $28.0 \%, 92.6 \%, 100.0 \%$ and $99.0 \%$ respectively. Groups with lower serological immunity levels were women aged less than 25 years, those reporting no history of vaccination and those living in Akre, Bardarash or Shekhan districts of Duhok. Tetanus immunity determined by seroprevalence of tetanus antitoxin levels exceeded that estimated by vaccination history, and serological markers should be used instead of vaccination history in determining immunity status.

Séroprévalence des anticorps antitétaniques chez des femmes enceintes dans le Gouvernorat de Duhok (Iraq)

RÉSUMÉ La vaccination des mères par l'anatoxine tétanique est la méthode la plus efficace de prévention du tétanos néonatal. À Duhok (Iraq), les données indiquent que la couverture vaccinale est faible. La présente étude a évalué le statut vaccinal pour l'anatoxine tétanique de 600 femmes enceintes sélectionnées aléatoirement et consultant I'hôpital universitaire Azadi à Duhok, pour leur accouchement. La méthode ELISA a permis de déterminer la séroprévalence de l'anatoxine tétanique et les antécédents des patientes en la matière. Les critères de l'Organisation mondiale de la Santé pour les taux protecteurs ont été utilisés pour la séroprévalence et les antécédents de vaccination. Globalement, $90 \%$ des femmes à l'accouchement avaient des titres d'antitoxine tétanique protecteurs par rapport à seulement $55 \%$ des femmes considérées comme protégées selon leurs antécédents de vaccination. Les taux d'immunité chez les femmes n'ayant pas reçu de vaccination antitétanique, ou ayant reçu une dose, deux doses ou trois doses ou moins représentaient $28,0 \%, 92,6 \%, 100,0 \%$ et $99,0 \%$ respectivement. Les groupes présentant les niveaux d'immunité sérologiques les plus faibles étaient composés de femmes de moins de 25 ans ou n'ayant jamais été vaccinées ou vivant dans les districts d'Akre, de Bardarash ou de Shekhan du gouvernorat de Duhok. L'immunité antitétanique déterminée par la séroprévalence des taux d'antitoxine tétanique surpassait celle estimée à partir des antécédents de vaccination. Par conséquent, les marqueurs sérologiques devraient être utilisés à la place des antécédents vaccinaux pour déterminer le statut immunitaire.

'Maternal and Child Health Care Section, Department of Preventive Health, Duhok General Directorate of Health, Duhok, Iraq. ${ }^{2}$ Department of Family and Community Medicine; ${ }^{3}$ Department of Microbiology, Duhok College of Medicine, Duhok, Iraq (Correspondence to Q.S. Habeeb:qayser_habeeb@yahoo.com).

Received: 27/03/11; Accepted: 19/05/11 


\section{Introduction}

Neonatal tetanus is still a relatively common disease with high mortality among neonates in several developing countries, including Iraq. Incidence rates of more than 1 per 1000 live births are documented in some areas [1], and the disease is responsible for about $14 \%$ of all annual neonatal deaths, claiming about 180000 lives worldwide every year $[2,3]$. The disease can, however, be easily prevented mainly by maternal immunization with tetanus toxoid (TT) vaccine and by aseptic obstetric and postnatal care practices [4]. The efficacy of the $\Pi T$ vaccine before and during pregnancy in preventing neonatal tetanus has been demonstrated [5-7]. Although subject to debate, measurement of tetanus antitoxin specific $\operatorname{Ig} G$ has been used as a monitor of protection and various studies suggest that the minimum level of antibody required for protection is $0.01 \mathrm{IU} / \mathrm{mL}$ [8].

According to the Duhok Directorate of Health, coverage of $\mathrm{TT} 2+(2$ or more $\Pi \mathrm{T}$ injections) for 2007 was $30.0 \%$, for 2008 was $31.7 \%$ and for 2009 was $32.7 \%$. However, this cannot be considered an indicator of the immunity situation due to recording, reporting and coverage calculation constraints [9]. In Iraq the multiple indicator cluster survey (MICS) implemented in 2006 showed that the percentage of mothers with a birth in the last 12 months protected against tetanus was $61.4 \%$ for Iraq, 59.4\% for Kurdistan and 50.1\% for Duhok province [10]. The World Health Organization (WHO) standard 30 clusters survey conducted by the Regional Ministry of Health and UNICEF in Kurdistan in 2007 showed that the percentage of mothers protected against tetanus at the time of delivery was 31.3\% for Duhok, 52.6\% for Sulemaniya and 58.4\% for Erbil [11].

This low protection was considered one of the main obstacles facing the Expanded Programme on Immunization (EPI) in Duhok Governorate.
However, it was thought that these figures did not indicate the real coverage or immunity against tetanus in the governorate. Exhaustive literature searches could not trace any previous study in Iraq that assessed serological immunity against neonatal tetanus apart from 1 study that assessed the efficacy of the vaccine in 1996 [12].

The aim of this study therefore was to determine the seroprevalence of tetanus antitoxin levels among pregnant women in Duhok, and its relation to TT history, age and residence.

\section{Methods}

\section{Study design and setting}

A cross-sectional seroprevalence study was conducted in Duhok Governorate/ Iraqi Kurdistan Region. The Governorate is composed of 7 districts: Duhok, Shekhan, Sumel, Zakho, Amedy, Akre and Bardarash. Participants were enrolled at Azadi Teaching Hospital which is the only tertiary hospital in the governorate. It receives referred labour cases (normal, complicated and emergency) from all districts.

\section{Study sample}

The sample comprised women attending Azadi teaching hospital for delivery between 16 March and 2 May 2009 and who were eligible for inclusion. A woman was considered eligible when prepared for admission to the delivery room (for second stage management) or to the operation theatre (for caesarean section). Exclusion criteria were: pregnant women attending from other provinces, and cases with blood sampling errors including inadequate volume, and haemolysed, lipaemic and icteric samples.

\section{Sample size and enrolment}

The estimated mid-year population of Duhok Governorate for 2008 was 985946 with 39438 expected annual deliveries [9]. The required sample size was determined according to the formula $[13]: n=\left(z^{2} \times 1-a / 2\right)(1-p) /\left(e^{2} \times p\right)$, where $\left(z^{2} \times 1-a / 2\right)=95 \%$ confidence interval, $a=$ alpha level $(0.05), p$ is the assumed prevalence of immunity against tetanus (0.31) [11], and e is the relative precision (0.15). Thus the estimated sample size was 380 . The number was increased to increase sample homogeneity and sampling proportional to district size was done to enhance representativeness.

A systematic random sampling procedure was used to enrol every fourth eligible pregnant women until the assigned proportion for each district was achieved. Thus a total of 600 eligible pregnant women were included in the study.

\section{Determination of immune status}

Immune status for tetanus was assessed in 2 ways.

Anti-tetanus-IgG antibody level. In accordance with WHO standards, IgG levels $>0.15 \mathrm{IU} / \mathrm{mL}$ were considered protective [8].

Vaccination history. In accordance with WHO recommendations, women were considered immune if they had received: i) 2 doses of $T T$ vaccine in the current pregnancy, or ii) 1 dose in the current pregnancy and $\geq 1$ previously, or iii) no doses in current pregnancy but $\geq 2$ doses previously. Women were considered non-immune at the time of the current delivery if they had received: i) 1 dose only of TT vaccine in the current pregnancy or previously, or ii) no doses in the current pregnancy and $\geq 2$ doses previously but not within the expected period of protection at the time of the last delivery, or iii) no doses in current pregnancy and $\geq 2$ doses previously but the date of and years since the last dose was not remembered, or iv) no doses in the current pregnancy or previously [14].

\section{Data collection}

A detailed immunization history of the mothers was obtained either from her 
immunization card, if available, or otherwise according to her recollection of immunization.

A $5 \mathrm{~mL}$ blood sample was drawn into a clean plain tube without anticoagulant and incubated in a water bath at $37^{\circ} \mathrm{C}$ for optimal separation followed by centrifugation at 2000-3000 rpm for 10 minutes. The sera were separated in plain tubes. Then $1 \mathrm{~mL}$ serum was transferred to a crayon vial (special laboratory tube fit for deep freezing and long-distance transportation) and stored at $-40{ }^{\circ} \mathrm{C}$ until transferred by air in a cool-box with frozen ice packs to the WHO regional laboratory in Muscat, Oman for estimation of tetanus antitoxin IgG level. The SERION ELISA classic Tetanus IgG kit was used (Virion \Serion, Germany). The ELISA assay procedure was carried out using BioMérieux ELISA reader 25 with Lab Systems Inc. well washer 4 [8].

\section{Ethical considerations}

The study was approved by the Research Ethics Committee. Women were informed about the objectives of study and their written consent to participate obtained. None refused to participate.

\section{Data analysis}

Data were analysed using SPSS, version 16 and Epi Info, version 3.5.1. For categorical variables, frequency and proportions were computed, and proportions were compared using the chi-squared test. A $P$-value less than 0.05 was considered statistically significant.

\section{Results}

Over $50 \%$ of the pregnant women enrolled were aged 18-29 years. The majority $(87 \%)$ were housewives and about $50 \%$ were illiterate. About $75 \%$ of the women reported seeking antenatal care services during the current pregnancy.

Table 1 shows serum levels of tetanus antitoxin $\operatorname{IgG}$. The first 2 groups were seronegative with titres up to 0.15
$\mathrm{IU} / \mathrm{mL}$; they represented $10.0 \%$ of the sample with the rest considered immune, with IgG antibody levels > $0.15 \mathrm{IU} / \mathrm{mL}$. The majority of women (63.7\%) had anti-tetanus IgG antibody levels $>1.0 \mathrm{IU} / \mathrm{mL}$.

Table 2 shows that seropositivity increased with increasing age as reflected by the high non-immune rates (20.8\%) in the age group under 18 years compared to those $\geq 35$ years ( $4.2 \%$ ).

Table 3 shows antibody levels by district. The highest rate of immunity was among women from Amedy (94.4\%), followed by Duhok (94.0\%), Sumel (93.9\%) and Zakho (89.7\%); the lowest rate was among women from Akre (80.8\%).

Table 4 shows that among women who never received $T T$ vaccination during pregnancy or adulthood, only $28 \%$ were immune, compared with $92.6 \%$ and $100 \%$ for those receiving 1 and 2 TT doses respectively. It also shows that only $13.8 \%$ of those who did not receive vaccination during the current pregnancy were non-immune, and this decreased to $3.6 \%$ and $0.0 \%$ among those who received 1 and 2 doses of $T \mathrm{~T}$ respectively in the current pregnancy.

Table 5 shows the correlation between tetanus immunity according to TT history and immunity according to anti-tetanus IgG seroprevalence. According to mothers' verbal histories, 331 (55.2\%) were considered protected at the time of their current delivery. Two women were later found to be non-immune by blood test. The other 329 were divided into 3 subcategories: first, those reported to have received 2 injections of TT during their current pregnancy 105 (17.5\% of the total sample); second, those reported to have received $1 \mathrm{TT}$ dose during their current pregnancy and at least 1 dose previously 69 (11.5\%). Third, those with no vaccination in the current pregnancy but with $\geq 2 \pi$ injections previously and still within the protection time 155 (25.8\%).

\begin{tabular}{lcc}
\hline \multicolumn{3}{l}{ Table 1 Distribution of study sample by tetanus antitoxin IgG level } \\
\hline IgG level (IU/mL) & No. (\%) & Cumulative \% \\
$<0.016$ & $5(0.8)$ & 0.8 \\
$0.016-0.15$ & $55(9.2)$ & 10.0 \\
$0.16-0.5$ & $69(11.5)$ & 21.5 \\
$0.51-1.0$ & $89(14.8)$ & 36.3 \\
$1.1-5.0$ & $268(44.7)$ & 81.0 \\
$>5.0$ & $114(19.0)$ & 100 \\
Total & $600(100)$ & \\
\hline
\end{tabular}

Table 2 Tetanus immunity $(\operatorname{lgG}>0.15 \mathrm{IU} / \mathrm{mL})$ among the study sample by age group

\begin{tabular}{lccc}
\hline Age group (years) & \multicolumn{2}{c}{ Immunity status } & Total \\
& Immune & Non immune & \\
\hline 18 & $19(79.2)$ & No. (\%) & \\
$18-24$ & $126(83.4)$ & $25(16.6)$ & 24 \\
$25-29$ & $177(90.3)$ & $19(9.7)$ & 151 \\
$30-34$ & $104(94.5)$ & $6(5.5)$ & 196 \\
$35+$ & $114(95.8)$ & $5(4.2)$ & 110 \\
Total & $540(90.0)$ & $60(10.0)$ & 119 \\
\hline
\end{tabular}

$\chi^{2}=17.333, d f=4, P=0.002$. 


\begin{tabular}{lccc}
\hline Table 3 Tetanus immunity & $(\mathbf{I g G}>\mathbf{0 . 1 5} \mathbf{~ I U} / \mathbf{m L})$ among the study sample by district \\
\hline District & \multicolumn{2}{c}{ Immunity status } & Total \\
& No. (\%) & Non-immune & \\
Amedy & $51(94.4)$ & $3(5.6)$ & 54 \\
Duhok & $158(94.0)$ & $10(6.0)$ & 168 \\
Sumel & $62(93.9)$ & $4(6.1)$ & 66 \\
Zakho & $113(89.7)$ & $13(10.3)$ & 126 \\
Shekhan & $47(87.0)$ & $7(13.0)$ & 54 \\
Bardarash & $46(85.2)$ & $8(14.8)$ & 54 \\
Akre & $63(80.8)$ & $15(19.2)$ & 78 \\
Total & $540(90.0)$ & $60(10.0)$ & 600 \\
\hline
\end{tabular}

$x^{2}=14.698, d f=6, P=0.023$.

There were 269 (44.8\%) women considered non-immune at the time of the current delivery according to their self-reported $T T$ history: 75 reported never having had a $T T$ injection, and 166 reported having had $\geq 2$ injections but were no longer within the period of protection at time of the current delivery, or the date of and years since the last TT dose was not remembered.

Despite the high rates of nonimmunity according to vaccination history, there were high rates of serological immunity. Only those who had never received $\Pi$ vaccination in their current pregnancy or previously had low immunity 28.0\% (21 mothers out of 75 who reported such history).

\section{Discussion}

Part of the national immunization programme in Iraq is providing vaccination to all pregnant women during the second and third trimesters of pregnancy. It is usually difficult to assess coverage reliably on the basis of reports of $T \mathrm{~T}$ doses administered and determination of tetanus antitoxin levels is the most reliable indicator yielding a more accurate estimate of protection; it is also a good way to monitor the effectiveness of any vaccination strategy for pregnant women $[15,16]$.

Data from the EPI unit during the last 10 years indicate that $\Pi \mathrm{T} 1$ and $\mathrm{T} 2+$ coverage rates for both pregnant women and women of child-bearing age never reached 50\% in Duhok [17]. Previous studies that estimated tetanus immunity in Duhok and in the Kurdistan region by vaccination coverage rates, revealed that tetanus immunization was inadequate [11]. The only serological study carried out in Duhok in 1996 assessed the efficacy of the vaccine and campaigns. It was based on a passive haemagglutination assay and could not estimate the prevalence among pregnant women because the study enrolled a total of 268 previously vaccinated individuals. The study, nevertheless, showed that 40 out of 50 women $(80 \%)$ had protective antibody levels which, $>0.01 \mathrm{IU} / \mathrm{mL}$ according to the assay used [12].

Tetanus immunity status among pregnant women in this study was analysed in reference to $T$ vaccinations regardless of diphtheria, pertussis, tetanus (DPT)/diphtheria, tetanus (DT) vaccinations in their childhood because dependence on childhood vaccination history could have resulted in added recall bias.

Indirect ELISA techniques are simple, sensitive, rapid and inexpensive tools for mass screening of the population but are generally less specific than the in vivo neutralization method. Good correlation between the indirect ELISA and neutralization assays has been demonstrated, although this is

\begin{tabular}{|c|c|c|c|c|c|}
\hline \multirow[t]{3}{*}{ No. of doses of TT } & \multicolumn{2}{|c|}{ Immunity status } & \multirow[t]{3}{*}{ Total } & \multirow[t]{3}{*}{$x^{2}$} & \multirow[t]{3}{*}{$P$-value } \\
\hline & Immune & Non-immune & & & \\
\hline & No. (\%) & No. (\%) & & & \\
\hline \multicolumn{6}{|l|}{ Ever received } \\
\hline 0 & $21(28.0)$ & $54(72.0)$ & 75 & \multirow{4}{*}{3.674} & \multirow{4}{*}{$<0.0001$} \\
\hline 1 & $25(92.6)$ & $2(7.4)$ & 27 & & \\
\hline 2 & 104 (100) & $0(0.0)$ & 104 & & \\
\hline$>2$ & $390(99.0)$ & $4(1.0)$ & 394 & & \\
\hline \multicolumn{6}{|c|}{ In current pregnancy } \\
\hline 0 & $355(86.2)$ & $57(13.8)$ & 412 & \multirow{4}{*}{22.16} & \multirow{4}{*}{$<0.0001$} \\
\hline 1 & $80(96.4)$ & $3(3.6)$ & 83 & & \\
\hline 2 & $105(100.0)$ & $0(0.0)$ & 105 & & \\
\hline Total & $540(90.0)$ & $60(10.0)$ & 600 & & \\
\hline
\end{tabular}

$\pi=$ tetanus toxoid. 


\begin{tabular}{|c|c|c|c|c|}
\hline \multirow[t]{3}{*}{ TT history } & \multicolumn{2}{|c|}{ Seropositivity } & \multirow[t]{3}{*}{ Total } & \multirow[t]{3}{*}{$P$-value ${ }^{a}$} \\
\hline & Immune & Non-immune & & \\
\hline & No. (\%) & No. (\%) & & \\
\hline \multicolumn{5}{|l|}{ Considered immune at time of current delivery } \\
\hline 2 doses in current pregnancy & $105(100.0)$ & $0(0.0)$ & 105 & \multirow{4}{*}{0.046} \\
\hline 1 dose in current pregnancy and $\geq 1$ previously & $69(97.2)$ & $2(2.8)$ & 71 & \\
\hline $\begin{array}{l}\text { None in current pregnancy, but } \geq 2 \text { previously } \\
\text { (and the mother still in the expected period of } \\
\text { protection at time of her current delivery) }\end{array}$ & $155(100)$ & $0(0.0)$ & 155 & \\
\hline $\begin{array}{l}\text { Total for immune cases at time of delivery } \\
\text { according to TT history }\end{array}$ & $329(99.4)$ & $2(0.6)$ & 331 & \\
\hline \multicolumn{5}{|l|}{ Considered non-immune at time of current delivery } \\
\hline 1 dose only in current pregnancy or previously & $26(92.9)$ & $2(7.1)$ & 28 & \multirow{6}{*}{$<0.001$} \\
\hline $\begin{array}{l}0 \text { doses in current pregnancy and } \geq 2 \text { previously, } \\
\text { but the mother no longer in the expected period of } \\
\text { protection at time of current delivery }\end{array}$ & $41(100.0)$ & $0(0.0)$ & 41 & \\
\hline $\begin{array}{l}0 \text { doses in current pregnancy and } \geq 2 \text { previously, } \\
\text { but date of and years since last dose not } \\
\text { remembered }\end{array}$ & $123(98.4)$ & $2(1.6)$ & 125 & \\
\hline 0 doses in current pregnancy or previously & $21(28.0)$ & $54(72.0)$ & 75 & \\
\hline $\begin{array}{l}\text { Total for non-immune at time of delivery according } \\
\text { to } T \text { history }\end{array}$ & $211(78.4)$ & 58 (21.6) & 269 & \\
\hline Grand total & $540(90.0)$ & $60(10.0)$ & 600 & \\
\hline
\end{tabular}

${ }^{a}$ Fisher exact test.

$\Pi=$ tetanus toxoid.

generally when antibody concentrations are above $0.16-0.2 \mathrm{IU} / \mathrm{mL}[18]$. Indirect ELISA, however, overestimates titres lower than this range when compared to the neutralization assay [19]. An antitoxin concentration above 0.15 $\mathrm{IU} / \mathrm{mL}$ is the preferred correlate of protection based on the results of ELISA $[8,20]$, which was applied in our study as a cut-off point between immune and non-immune cases.

In Ankara, Turkey a similar study using ELISA testing in pregnant women at the time of delivery revealed an immunity rate of $69 \%$ using a cut-off level $\geq 0.6 \mathrm{IU} / \mathrm{mL}$. Other studies have investigated the community in general and not just pregnant women or women of child bearing age, also using ELISA testing and a $0.15 \mathrm{IU} / \mathrm{ml}$ cut-off; thus an immunity rate of $80 \%$ was found in the Kocaeli region in Turkey [21], 68\% in Egypt [22] and $72 \%$ in the Unites States of America [23]. In our study using the same test procedure and cut-off level, however, the immunity rate was higher (90\%). This may be attributed to different time periods of the studies; the previous studies were conducted between 2002 and 2005, while our study was done in 2009 after extensive WHO efforts to include $T T$ vaccination for pregnant females in the routine EPI programme in Iraq.

Despite thehigh antitoxin seroprevalence in the present study, only $54.8 \%$ of the mothers were considered protected according to their immunization history, which similar to what has been found in previous local surveys $[10,11]$. Only $10 \%$ of the sample were seronegative $(\leq 0.15 \mathrm{IU} / \mathrm{mL})$. This finding contrasts with the large number of women who were considered non-immune at the time of current delivery. This discrepancy highlights the mismatch between the proposed protective antibody cut-off level and the immunity status gauged by reasonably dependable history data. It is interesting to note that if the cut-offlevel were raised to $1.0 \mathrm{IU} / \mathrm{ml}$, the non-immune women would constitute $36.3 \%$ of the sample, which represents a better match between serological protection and history data.

In contrast to several previous studies, antibody protective levels increased with increasing age [21]. This may be due to the fact that our study included only pregnant women, i.e. only those of child-bearing age ( 15 to 49 years), and those were the ages of women who were included in the neonatal tetanus elimination programme initiated in the early 1980s. The lower rate of immunity exhibited by those under 18 years of age (79.2\%) may be attributed to the waning immunity from their uncompleted TT vaccination or to childhood DPT vaccination.

For mothers who reported receiving no vaccination, only $28.0 \%$ were found immune by IgG level. This is consistent with results obtained in other studies such as in Turkey [21] and the Central 
African Republic [14]. Underreporting of TT doses may be the main reason.

Overall sample assessment by vaccination history revealed 55.2\% immune. Almost all mothers who were expected to be immune at delivery according to their immunization history (99.4\%) showed high immunity status reflected by antibody titres of more than $0.15 \mathrm{IU} /$ $\mathrm{mL}$. This was found even among those who had received no vaccination during the current pregnancy, but apparently had achieved the $\operatorname{IgG}$ threshold earlier. On the other hand $78.4 \%$ who were not expected to be immune at delivery according to their immunization history had high antibody titres including even $28 \%$ of those with no vaccination history. These results are similar to those found in the Central African Republic [14]. This may be due to underreporting or to their past childhood immunization with DPT.

\section{Conclusions and recommendations}

Tetanus immunity determined by serological markers exceeds that estimated by vaccination history and those reported by the previous local surveys. Accordingly, and if facilities and resources are available, it is advisable to depend on seroprevalence of antibody titres especially when data recorded on cards are not easily available.

\section{Acknowledgement}

We would like to thank WHO for help in the analysis of the samples at their central laboratory in Muscat, Oman.

\section{References}

1. Blencowe $\mathrm{H}$ et al. Tetanus toxoid immunization to reduce mortality from neonatal tetanus. International Journal of Epidemiology, 2010, 39(6):i102-i109.

2. Tetanus vaccine. Weekly Epidemiological Record, 2006. 20:198-208 (http://www.who.int/wer/2006/wer8120.pdf, accessed 23 April 2012).

3. Dikici B et al. Neonatal tetanus in Turkey; what has been changed in the last decade? BMC Infectious Diseases, 2008, 8:112-118.

4. Pickering LK, ed. Report of the Committee on Infectious Diseases, 28th ed. Elk Grove Village, American Academy of Pediatrics, 2009.

5. Atkinson $\mathrm{W}$ et al., eds. Epidemiology and prevention of vaccinepreventable disease, 11 th ed. Washington DC, Public Health Foundation, 2009

6. Public Health Agency of Canada. Canadian immunization guide, seventh edition - 2006, part 3 (http://www.phac-aspc. gc.ca/publicat/cig-gci/p03-eng.php, accessed 23 April 2012).

7. Alrawi AG, Al-Obaidy M. Factors contributing to the decline in the incidence of tetanus neonatorum in Iraq. Iraqi Medical Journal, 1990, 39:132-136.

8. Borrow DR, ed. The immunological basis for immunization series module 3: tetanus update 2006. Geneva, World Health Organization, 2007.

9. Statistics Unit, Planning Department, Duhok Department of Health, 2009.

10. Multiple Indicator Cluster Survey 2006, Final Report. Iraq, Central Organization for Statistics \& Information Technology and Kurdistan Regional Statistics Office, UNICEF, Ministry of Health, 2007 (http://www.childinfo.org/files/MICS3_Iraq_FinalReport_2006_eng.pdf, accessed 23 April 2012).

11. Household immunization coverage survey. Erbil, Kurdistan Region Government, Iraq Ministry of Health, UNICEF, 2007.
12. Al-Bamarny A. Evaluating the anti-tetanus vaccination campaign in Duhok by determining the antibody response in vaccinated individuals [MSc thesis]. Erbil, Iraq, University of Salahaddin, College of Science, 1996.

13. Lwanga SK et al. Teaching health statistics, 2nd ed. Geneva, World Health Organization, 1999.

14. Deming $\mathrm{M}$ et al. Tetanus toxoid coverage as an indicator of serological protection against neonatal tetanus. Bulletin of the World Health Organization, 2002, 80:696-703.

15. Maral I et al. Serum levels of antitetanus antibodies at time of delivery. European Journal of Epidemiology, 2001, 17:661-665.

16. Stroh G, Birmingham M. Protocol for assessing neonatal tetanus mortality in the community using a combination of cluster and lot quality assurance sampling. Bulletin of the World Health Organization, 2002, 65:309-316.

17. Annual programs review. Duhok, Duhok Directorate of Health Press, 2008.

18. Simonsen $\mathrm{O}$ et al. ELISA for the routine determination of antitoxic immunity to tetanus. Biologicals, 1986, 14:231-239.

19. Dokmetjian J et al. A possible explanation for the discrepancy between ELISA and neutralising antibodies to tetanus toxin. Vaccine, 2000, 18:2698-2703.

20. Galazka AM. The immunological basis for immunization series module 7: general immunology. Geneva, World Health Organization, 1993.

21. Dundar V et al. Prevalence of tetanus immunity in the Kocaeli Region, Turkey. Japanese Journal of Infectious Diseases, 2005, 58:279-282.

22. Redwan ERM, Al-Awady MK. Prevalence of tetanus immunity in the Egyptian population. Egyptian Journal of Immunology, 2002, 11:55-59.

23. Maselle SY et al. Serologic Immunity to diphtheria and tetanus in the United States. Indian Pediatrics, 2002, 17:797-801. 